\title{
Risk factors of branch retinal vein occlusion (BRVO) a study at tertiary care centre
}

\author{
Khushnood M. Sheikh,", Manisha Shashtri ${ }^{2}$, Ombir Singh ${ }^{3}$ \\ ${ }^{\mathbf{1}}$ Associate Professor, ${ }^{2}$ Professor, ${ }^{3}$ Consultant, Dept. of Ophthalmology, Surat Municipal Institute of Medical Education and \\ Research, Surat, Gujarat, India
}

*Corresponding Author:

Email: kmsheikh69@gmail.com

\begin{abstract}
Introduction: Retinal vein occlusion is second most common retinal vascular disorder after diabetic retinopathy. BRVO caused due to occlusion of branch vein of retina with involvement of particular quadrant. On ophthalmoscopic examination patient will have retinal edema and or macular edema with superficial and deep retinal haemorrhages and venous dilatation within the affected sector. The most recognized risk factor for BRVO are age and systemic vascular disorders.

Materials and Methods: Prospective observational study was done for the period of one year. Patients more than 30 years of age attending ophthalmology OPD found to have BRVO were evaluated for various risk factors after taking consent. History and thorough eye examination were carried out including fundus photography and fluorescein angiography.

Results: In this study 38 patients of more than 30 years (32-75 years) found to have BRVO out of which 21 were male and 17 were female. 25 cases $(65.78 \%)$ (p-value 0.0384$)$ having hypertension, 8 case $(21.05 \%)$ (p-value 0.135$)$ having diabetes, 7 $(18.42 \%)$ (p-value 0.04) were smokers, 13 (34.21\%) (p-value 0.0008) were having altered lipid profile, $15(65.22 \%)(\mathrm{p}$ value < $0.001)$ out of 23 cases were having higher homocysteine level.2 cases (5.26\%) were alcoholics. All these diseases are causing BRVO in a combination.

Conclusion: With the help of modern instrument and technology branch retinal vein occlusion can be easily diagnosed and treated. It is a multi-factorial disease affect the eyes of an individual having hypertension with other risk factors like ageing, hyperlipidaemia, homocysteinemia etc. so beware of four $\mathrm{H}$, higher age, hypertension, hyperlipidaemia, homocysteinemia
\end{abstract}

Keywords: BRVO, Diabetes mellitus, Hypertension, Homocysteinemia, Smoking.

\section{Introduction}

Retinal Vein Occlusion (RVO) is the second most common retinal vascular disorder after diabetic retinopathy. It is the most common macro vascular disease entity of retina seen in clinical practice. BRVO was first described by Leber a German ophthalmologist in $1877^{1}$ since then there has been a disagreement on diagnostic features of this clinical entity.

It is noted that two third of retinal vein occlusion develops supero-temporarily and one third develops infero-temporally. ${ }^{2}$ The most recognized risk factors for BRVO are age and systemic vascular disorder. A very basic and important fact in pathogenesis of BRVO is that like all ocular vascular occlusion disorder BRVO is multifactorial in origin. Since most of the studies on BRVO performed in white populations. ${ }^{3}$ Limited studies have been performed in Asian populations hence this study is carried out to identify the risk factors of BRVO.

\section{Materials and Methods}

It is a prospective observational study carried out at tertiary care center for period of 12 months.

Inclusion Criteria: All the patients of 30 years of age and older having BRVO. Those giving consent to enroll in study

\section{Exclusion Criteria:}

1. Subjects having proliferative diabetic retinopathy with vitreous haemorrhage ( $\mathrm{VH})$.
2. Subjects having $\mathrm{VH}$ corneal opacity and mature cataract.

3. Eyes with hemi retinal vein occlusion were excluded from study as regarded as CRVO.

\section{Methodology}

In this study patients of $>30$ years of age who diagnosed to have BRVO on routine fundus examination and having complain of sudden painless blurring of vision were evaluated.

1. Brief history of all patients including chief complain, origin, duration and progression of symptoms, associated systemic illness and their treatment were noted.

2. The patient's history of ocular surgery was also determined.

3. V/A assessment was done.

4. IOP was measured by using NON-contact tonometry.

5. SLE and fundus examination by $78 \mathrm{D}$ and 20D was done.

6. The findings of fundus examination were recorded in terms of types of BRVO and location of it.

7. Confirmatory test - Fundus photograph, FFA

We consider age, sex, hypertension, diabetes, smoking, alcohol intake, lipid profile, homocysteine level as possible risk factors for BRVO. of $\mathrm{Hg}$. 
DM was defined as blood sugar $>125 \mathrm{mg} / \mathrm{dl}$, PPBS $>220 \mathrm{mg} / \mathrm{dl}$ orHb1Ac $>6.5$ homocystenimia defined as level $>15 \mathrm{mmol} / \mathrm{lit}$.

\section{Results and Discussion}

We have detected 38 patients having BRVO during our study for a period of 1 year, out of 38 BRVO cases 21 were male and 17 were female. Study shows male preponderance which is comparable in other studies ${ }^{6}$ higher hematocrit and hormonal basis in males could act as a contributory factor in elevating blood viscosity and producing BRVO. Gutenberg health study ${ }^{15}$ in 2015 shows that prevalence of RVO increases with age.

Table 1: Sex wise distribution

\begin{tabular}{|l|c|c|}
\hline Male & Female & Total \\
\hline 21 & 17 & 38 \\
\hline
\end{tabular}

Table 2: Age wise distribution

\begin{tabular}{|l|c|c|}
\hline Age & Male & Female \\
\hline $30-40$ & 2 & 0 \\
\hline $41-50$ & 3 & 5 \\
\hline $51-60$ & 6 & 4 \\
\hline $61-70$ & 10 & 6 \\
\hline$>71$ & 0 & 2 \\
\hline
\end{tabular}

\section{Risk Factors}

Hypertension: 25 out of 38 cases of BRVO having history of hypertension. Out of these 9-patient were having hypertension only as a risk factor while 16 patients were detected hypertension associated with other risk factor during study period.

Table 3: Division of BRVO cases according hypertensive category

\begin{tabular}{|l|c|c|c|}
\hline $\begin{array}{l}\text { Stage of hypertension } \\
\text { according to JNC-VII }\end{array}$ & $\begin{array}{c}\text { Systolic blood } \\
\text { pressure }\end{array}$ & $\begin{array}{c}\text { Diastolic blood } \\
\text { pressure }\end{array}$ & $\begin{array}{c}\text { No. o BRVO } \\
\text { cases }\end{array}$ \\
\hline Normal & $<120 \mathrm{mmHg}$ & $<80 \mathrm{mmHg}$ & 2 \\
\hline Pre-hypertension & $120-139 \mathrm{mmHg}$ & $80-89 \mathrm{mmHg}$ & 13 \\
\hline Stage- I Hypertension & $140-159 \mathrm{mmHg}$ & $90-99 \mathrm{mmHg}$ & 11 \\
\hline Stage-II Hypertension & $\geq 160 \mathrm{mmHg}$ & $\geq 100 \mathrm{mmHg}$ & 12 \\
\hline
\end{tabular}

Newman- Casey PA et $\mathrm{al}^{16}$ assessed the risk factors associated with developing BRVO, they found that HT alone or along with DM and hyperlipidemia had an increased hazard of developing a BRVO compared with those with none of these conditions.

Other studies mentioned that hypertension is having strong association with the occurrence $\operatorname{BRVO}(9,15)$ Data of our BRVO cases also shows HT as a risk factor [25 cases out of $38,65.79 \%$ at $95 \%$ CI: $48.65 \%$ to $80.37 \%$ ] This finding is consistent with other case series reported $55 \%$ to $75 \%$ of BRVO. ${ }^{10}$

Diabetes: There were 8 BRVO cases $(21.05 \%, 95 \%$, CI: $9.55 \%$ to $37.32 \%$ ) in this study having history of diabetes at time of presentation 6 patients out of them were having RBS $>140 \mathrm{mg} / \mathrm{dl}$ while 2 patients were having blood glucose less than that. Out of total 8 diabetic cases 6 patients have associated hypertension so only 2 patients $(5.26 \%, 95 \%$, CI: $0.64 \%$ to $17.74 \%)$ affected BRVO were having DM only as a risk factor. Lam HD et al ${ }^{7}$ CIEMS study ${ }^{14}$ also shows that BRVO was not significantly associated with the presence of $\mathrm{DM}(\mathrm{P}>0.10)$. Metanalysis by Petr Kolar ${ }^{5}$ shows that individual with end organ damage caused by DM having greatly increase risk of RVO i.e. CRVO only not BRVO.

Alcoholism and Smoking: 2 out of 38 cases (5.26\%, $95 \%$, CI: $0.64 \%$ to $17,74 \%$ ) were having $\mathrm{H} / \mathrm{O}$ alcoholism. Beaver dam eye study (BDES) ${ }^{3}$ does not consider alcohol consumption as a risk factor for BRVO and similar results found in CIEM $^{1}$ study. 7 out of 38 cases $(18.42 \%, 95 \%$ CI; $7.74 \%$ to $34.32 \%)$ were having history of smoking. In the eye disease case control study ${ }^{4}$ smoking was a risk factor for BRVO

In BDES $^{3}$ age adjusted current smoking (OR 4.43, 95\% CI; 1.53,12.84) compared with nonsmokers. SINDI study ${ }^{13}$ and meta-analysis by Petr Kolar ${ }^{5}$ also has a similar finding.

\section{Table 4: Systemic conditions associated with BRVO} cases

\begin{tabular}{|l|c|c|}
\hline $\begin{array}{l}\text { Systemic } \\
\text { condition }\end{array}$ & $\begin{array}{c}\text { No. of } \\
\text { cases }\end{array}$ & Percentage \\
\hline Hypertensives & 25 & $65.79 \%$ \\
\hline Diabetes & 8 & $21.05 \%$ \\
\hline Smokers & 7 & $18.42 \%$ \\
\hline Alcoholics & 2 & $5.26 \%$ \\
\hline
\end{tabular}

Lipid Profiles: Serum Lipid profiles alteration predisposes the vein for occlusive disease. Increase in LDL, TG and cholesterol and decrease in HDL put the vessels at risk of atherosclerosis and can lead to BRVO. In this study 13 out of 38 cases were having this risk factor $(34.21 \%, 95 \% \mathrm{CI} ; 19.63 \%$ to $51.35 \%)$. Dodson at al has reported a prevalence of hyperlipidemia of $54 \%$ among BRVO cases, ${ }^{11}$ study by Jaulim $\mathrm{A}^{17}$ and Lam $\mathrm{HD}^{7}$ also stated that the altered lipid profile is a proven risk factor for development of BRVO. BDES ${ }^{3}$ shows that after adjusting for age serum lipid level is not a risk factor for BRVO.

Serum Homocysteine level: 23 patients had got done serum homocysteine out of 38 patients. The normal value for S. Homocysteine $15 \mathrm{mmol} / \mathrm{lit}$. Out of 23 
patients those who had undergone S. homocysteine level 15 patients were having high level of $\mathrm{S}$. Homocysteine.

Table 5: Number of BRVO cases with altered lipid profile, high level of blood sugar, BP and homocysteine

\begin{tabular}{|l|c|c|}
\hline & No. of cases & Percentage \\
\hline High Blood pressure & 23 & $60.53 \%$ \\
\hline $\begin{array}{l}\text { High blood sugar } \\
\text { level }\end{array}$ & 6 & $15.79 \%$ \\
\hline Altered lipid profile & 13 & $34.21 \%$ \\
\hline High Homocysteine & 15 out of $23^{*}$ & $65.22 \%$ \\
\hline
\end{tabular}

*only 23 cases out of 38 get done Serum homocysteine level.

A study by Kapil D Lahiri ${ }^{18}$ in India analyzed total plasma homocysteine in 64 cases of retinal vein occlusion of which 24 cases of central retinal vein occlusion and 40 cases of BRVO homocysteine was significantly in increase in RVO case in respect to control $(p<0.001)$ S. homocysteine ${ }^{8,12}$ has been established as an independent risk factor for development of BRVO. Meta-analysis by Peter Kolar ${ }^{5}$ also supports these results.

Table 6: Analysis of risk factors ( $N=38$ )

\begin{tabular}{|l|c|c|c|}
\hline Disease & Single disease (A) & In combinations (B) & Significance \\
\hline HT & 9 & $16(42.10 \%)$ & P value $=0.0384$ \\
\hline Diabetes & $2(5.26 \%)$ & $6(15.78 \%)$ & P value 0.135 \\
\hline Smoking & $1(2.63 \%)$ & $6(15.78 \%)$ & P value 0.04 \\
\hline Alcohol & 0 & 2 & N.P. \\
\hline Lipid & $1(2.63 \%)$ & $12(31.58)$ & P value 0.0008 \\
\hline S.Homocysteine & $2(8.70 \%)$ & $13(56.52 \%)$ & P value $<0.001$ \\
\hline No risk factors(5) & --- & - & - \\
\hline
\end{tabular}

( $\mathrm{Z}$ test of proportion applied by using epitool software.)

1. Nine $(23.68 \%)$ patients only having the hypertension in contrast to the sixteen $(42.10 \%)$ patients are in the combination with other risk factor. ( $p$ value $=0.0384$ ).

2. Smoking in a combination can cause BRVO (p value $=0.04)$.

3. Altered serum lipid profiles with other risk factors can cause BRVO ( $\mathrm{p}$ value=0.0008).

4. Serum Homocysteine alone and in a combination, can cause BRVO ( $p$ value $<0.001$ ).

5. Out of 38 patients 18 patients are having multifactorial risk of BRVO, 15 patient having single disease while 5 patients do not have any disease.

\section{Conclusion}

It is observed that BRVO is a multifactorial disease which is common in males of above 40 years. Sedentary lifestyle and unhealthy dilatory habits increases the risk of hypertension and hyperlipidemia. Systemic hypertension, hyperlipidemia and homocysteinemia are main risk factors of BRVO out of which hypertension and homocysteinemia alone can cause BRVO.

\section{Acknowledgement}

I thankful to Dr. Swati Patel, assistant professor, community medicine for charting and calculations and residents of the ophthalmology department for their support.

\section{References}

1. Leber T. Die Krankheite der Netzhaut U. des Schnerven. In: Graefe-Saemisch Handbuch der Cesamten Augenheikunde. Leipzig, 1st ed., vol.5, pp. 531, 1877.

2. Z.Y. Du, J.Q. Tan and D.Y. Jiang, 1994. Patterns of arteriovenous crossings in branch retinal vein occlusion. Chinese J. Ophthalmol., 30:345-347.

3. Klein R, Klein BE, Moss SE, Meuer SM. The epidemiology of retinal vein occlusion: the beaver dam eye study. Trans Am Ophthalmol Soc. 2000;98:133-141.

4. Risk factors for branch retinal vein occlusion. The Eye Disease Case-control Study Group. Am J Ophthalmol. 1993 Sep 15; 116(3):286-96.

5. Kolar P. Risk Factors for Central and Branch Retinal Vein Occlusion: A Meta-Analysis of Published Clinical Data. J Ophthalmol. 2014; 2014:724780.

6. Appiah AP, Trempe CL. Risk factors associated with branch vs. central retinal vein occlusion. Ann Ophthalmol. 1989 Apr; 21(4):153-5,157.

7. Lam HD, Lahey JM, Kearney JJ, et al. Young patients with branch retinal vein occlusion: a review of 60 cases. Retina 2010;30:1520-1523.

8. Clarke R, Daly L, Robinson K, Naughten E, Cahalane S, Fowler B, Graham I. Hyperhomocysteinemia: An independent risk factor for vascular disease. $N$ Engl. $J$ Med. 1991;324:1149-1155.

9. Shrestha RK, Shrestha JK, Koirala S, Shah DN. Association of systemic diseases with retinal vein occlusive disease JNMA. 2006;45:244-8.

10. Patz A, Yassur Y, Fine SL, Finkelstein D, Orth DH. Branch Retinal venous occlusion. Ophthalmol, 1977; 83:373-8.

11. Dodson PM, Galton DJ, Winder AF. Retinal Vascular abnormalities in the hyperlipidaemias. Trans Ophthalmol Soc U K. 1981;101(1):17-21.

12. Welch GN, Loscalzo J. Homocysteine and atherothrombosis. N Engl J Med. 1998;338:1142-1150.

13. Mayuri Bhargava; Victor Koch; Carol Cheung; Wan Ling Wong. Prevalence and risk factors of retinal vein 
occlusion in Asian Indians - comparative study between Singapore and India IOVS, June 2013, Vol.54, 1565.

14. Jonas JB, Nangia V, Khare A, Sinha A, Lambat S.

Prevalence and associations of retinal vein occlusions: the Central India Eye and Medical Study. Retina. 2013 Jan; 33(1):152-9.

15. Ponto KA, Elbaz H, Peto T, Laubert-Reh D, Binder H, Wild PS, Lackner K, Pfeiffer N, Mirshahi A. Prevalence and risk factors of retinal vein occlusion: the Gutenberg Health Study 2015 J Thromb Haemost 2015;13:1254-63.

16. Newman-Casey PA, Stem M, Talwar N, Risk factors associated with developing branch retinal vein occlusion among enrollees in a United States managed care plan. Ophthalmology. 2014 Oct; 121(10):1939-48.

17. Jaulim A, Ahmed B, Khanam T, Chatziralli IP. Branch retinal vein occlusion: epidemiology, pathogenesis, risk factors, clinical features, diagnosis, and complications. An update of the literature. RETINA 33:901-910, 2013.

18. Kapil D. Lahiri, Jayanta Dutta, Himadri Datta, and Harendra N. Das. Hyperhomocysteinemia, as an Independent Risk Factor for Retinal Venous Occlusion in an Indian Population, Indian J Clin Biochem, v.28 (1);2013 Jan. 